\title{
Associations between gross Motor Coordination and Academic Achievement in elementary school children
}

\author{
Luís Lopes ${ }^{\mathrm{a}, *}$, Rute Santos ${ }^{\mathrm{b}, \mathrm{c}}$, Beatriz Pereira ${ }^{\mathrm{a}}$, Vítor P. Lopes ${ }^{\mathrm{d}}$ \\ ${ }^{\text {a }}$ Research Centre on Child Studies (CIEC). Institute of Education, University of Minho, Portugal \\ ${ }^{\mathrm{b}}$ Research Centre for Physical Activity, Health and Leisure (CIAFEL), Faculty of Sports, University of Porto, Portugal \\ ${ }^{\mathrm{c}}$ Maia Institute of Higher Education, Portugal \\ ${ }^{\mathrm{d}}$ Research Center in Sports Sciences, Health Sciences and Human Development (CIDESD), Department of Sports Science of \\ Polytechnic Institute of Bragança, Portugal
}

\section{A R T I C L E I N F O}

\section{Article history:}

Available online 20 December 2012

\section{PsychINFO classification:}

2820

3550

3720

Keywords:

Motor coordination

Academic achievement

Cardiorespiratory fitness

Socio-economic status

Body mass index

\begin{abstract}
A B S T R A C T
We aimed to evaluate the relationship between gross motor coordination (MC) and academic achievement (AA) in a sample of Portuguese children aged 9-12 years. The study took place during the 2009/2010 school year and involved 596 urban children (281 girls) from the north of Portugal. AA was assessed using the Portuguese Language and Mathematics National Exams. Gross MC was evaluated with the Körperkoordination Test für Kinder. Cardiorespiratory fitness was predicted by a maximal multistage 20-m shuttle-run test of the Fitnessgram Test Battery. Body weight and height were measured following standard procedures. Socio-economic status was based on annual family income. Logistic Regression was used to analyze the association of gross MC with AA. 51.6\% of the sample exhibited MC disorders or MC insufficiency and none of the participants showed very good MC. In both genders, children with insufficient MC or MC disorders exhibited a higher probability of having low AA, compared with those with normal or good MC $(p<.05$ for trend for both) after adjusting for cardiorespiratory fitness, body mass index and socio-economic status.
\end{abstract}

(c) 2012 Elsevier B.V. All rights reserved.

\section{Introduction}

Mastery of a variety of motor skills is a requisite for children to engage in everyday activities and has important implications for different aspects of development in children and adolescents

\footnotetext{
* Corresponding author. Tel.: +351962803023.

E-mail address: luis.iec.um@hotmail.com (L. Lopes).
} 
(Piek, Baynam, \& Barrett, 2006). Children's motor skill development incorporates many body systems, including sensory, musculoskeletal, cardiorespiratory, and neurological systems (Dwyer, Baur, \& Hardy, 2009), as well as the child's ability to interact with the environment (Riethmuller, Jones, \& Okely, 2009). Consequently, the study of a child's motor development is a prerequisite for the full understanding of the child's whole development (Payne \& Isaacs, 1998).

The importance of promoting the development of MC at younger ages relies on the current and future benefits associated with the acquisition and the maintenance of motor proficiency (Lubans, Morgan, Cliff, Barnett, \& Okely, 2010). For instance, it has been suggested that an appropriate acquisition of MC contributes to children's physical, cognitive, and social development (Payne \& Isaacs, 1998). Furthermore, a proper MC level is essential for a strong general development, as well as for health, psychosocial development, and well-being (Haga, 2008; Piek et al., 2006). Childhood is a critical period for the development of these skills, which are considered building blocks of more complex movements (Clark \& Metcalfe, 2002) and represent a key factor in the promotion of lifelong active lifestyles (Clark, 2005; Stodden et al., 2008). It is also known that motor skills have been observed to track during childhood (Malina, 1996).

Recently, there is a re-emerged debate around the possible relations between physical activity (PA), physical fitness, motor coordination (MC) and cognitive development (Niederer et al., 2011), based on the decrease in children's PA (Knuth \& Hallal, 2009), physical fitness (Tomkinson \& Olds, 2007), MC (Prätorius \& Milani, 2004), and the pressure of schools and parents to improve cognitive performance (Chomitz et al., 2009; Ertl, 2006).

While the relationship between PA and physical fitness with academic achievement (AA) has been thoroughly explored (Ahamed et al., 2007; Carlson et al., 2008; Castelli, Hillman, Buck, \& Erwin, 2007; Chomitz et al., 2009; Coe, Pivarnik, Womack, Reeves, \& Malina, 2006; Etnier, Nowell, Landers, \& Sibley, 2006; Eveland-Sayers, Farley, Fuller, Morgan, \& Caputo, 2009; Fox, Barr-Anderson, Neumark-Sztainer, \& Wall, 2010; Grissom, 2005; Hillman, Erickson, \& Kramer, 2008; Kwak et al., 2009; Niederer et al., 2011; Rasberry et al., 2011; Ruiz et al., 2010; Sigfusdottir, Kristjansson, \& Allegrante, 2007; Strong et al., 2005; Taras, 2005; Trudeau \& Shephard, 2008), is known about the relation between gross MC and AA in elementary school children.

Studies suggest that neuronal structures (in the cerebellum and the frontal lobe) are responsible for coordination as well for cognition (Serrien, Ivry, \& Swinnen, 2006). There is also evidence that working memory capacity and visual perceptual ability limit children's AA (Alloway, 2007; Alloway \& Alloway, 2010; Sortor \& Kulp, 2003). Besides, one cross-sectional and longitudinal study found that higher baseline motor skills (agility and dynamic balance) were related to better spatial working memory and/or baseline attention as well as their future improvements over the following nine months (only no association was found between dynamic balance and attention) (Niederer et al., 2011). Indeed, children with developmental coordination disorders tend to perform poorly in literacy and numeracy assessments (Alloway, 2007), while fine MC was found to positively correlate with AA (Sortor \& Kulp, 2003), and children with learning disabilities scored poorer in gross MC test (both locomotor and object-control) (Westendorp, Hartman, Houwen, Smith, \& Visscher, 2011). Additionally, other cross-sectional (Knight \& Rizzuto, 1993; Nourbakhsh, 2006; Planinsec, 2002) and interventional studies (Budde, Voelcker-Rehage, Pietrabyk-Kendziorra, Ribeiro, \& Tidow, 2008; Erickson, 2008; Uhrich \& Swalm, 2007) have shown that improved motor skill levels may be positively related to improvements in AA or other cognitive variables. Moreover, longitudinal studies in preschool children found a relationship between early motor development and later cognitive function (Piek, Dawson, Smith, \& Gasson, 2008; Son \& Meisels, 2006), suggesting that early school motor skills assessment may increase the predictability of later achievement and the probability of identifying children at risk for school failure (Son \& Meisels, 2006).

It is important to note that the term "motor coordination" used in this study is a general term that encompasses various aspects of movement competency. There are many different test batteries that assess movement in a variety of ways using various movement tests. Specifically, process and product oriented movement assessments are used to examine differences in levels of MC. While it is outside the scope of this study to explain the differences and limitations in how movement and/or movement outcomes are assessed, we used the term "motor coordination" in this study as it specifically aligns with the language used in the assessment implemented for this study (Kiphard-Schilling body coordination test) and with previous literature that has used the same assessment. 
Despite these findings, to the best of our knowledge, no study to date has addressed the association between gross MC and direct/objective indicators for AA, namely scores on standardized tests, in elementary school children without intellectual disabilities, accounting for potential confounders such as physical fitness, body composition or socio-economic status (Carlson et al., 2008; Coe et al., 2006; Etnier et al., 2006; Kwak et al., 2009; Rasberry et al., 2011; Trudeau \& Shephard, 2008). In this context, understanding whether or not gross $\mathrm{MC}$ is related to AA among school age children may provide useful information about how to incorporate PA into daily life, helping to achieve recommended levels of PA and physical fitness and positively impacting academic success or progress. The purpose of the present study was to evaluate the relationship between gross MC and AA in urban Portuguese children aged 9-12 years, accounting for cardiorespiratory fitness, body mass index, and socio-economic status.

\section{Methods}

\subsection{Study design and sampling}

Data for the present study are derived from the Bracara Study, which aimed to evaluate the relations between gross MC, PA, physical fitness, body composition, AA and health behaviors among elementary school children. The Bracara Study was conducted in a middle city located in the north of Portugal during the 2009/2010 academic year.

\subsection{Participants}

All 21 public elementary schools in the city that qualified as urban (according to the Municipal Administration Registry) were considered and invited to participate in this study, corresponding to 846 children enrolling in the fourth grade; two schools decided not to take part in this study, corresponding to 90 children; six schools could not be evaluated on time to take part in this study, corresponding to 130 children; 30 children who failed the inclusion criteria (having a mental and/or physical disability or a health condition that did not allow them to participate in physical education classes) or had missing information on the variables of interest were excluded from this analysis. Therefore, the study included 13 urban public elementary schools, and 596 participants (281 girls) aged $9-12$ years old.

\subsection{Procedure}

The schools' directors and children's parents/guardians received verbal and written description of the study and signed a written informed consent form. The protocol and procedures employed followed the Helsinki Declaration for Investigation in Human Subjects and were approved by the Curricular Development and Innovation Division (Portuguese Ministry of Education) and by the University's Ethics Committee.

Two full-time assessors collected data during regularly scheduled physical education classesby. The assessors were physical education graduates who received specific training, and had already participated in previous KTK data collection. The assessors were helped by the physical education teachers.

\subsection{Measures}

\subsubsection{Academic achievement}

AA was assessed using the Portuguese Language and Mathematics National Exams that are mandatory for all 4th grade students. The exams were administered in May 2009 by two supervision teachers in the classroom. The Educational Evaluation Office from the Portuguese Ministry of Education performs management, analysis, and maintenance of student data and the National Exams database. The National Exams are criterion-referenced tests that provide scores to students, teachers and parents according to the performance levels: A (very good), B (good), C (fair), D and E (insufficient). For 
each exam 1, 2, 3, 4, or 5 points were attributed to scores of E, D, C, B, and A, respectively. An AA score was computed by summing the points attained for each of the exams. Participants were then categorized as having high $\mathrm{AA}$ ( $>8$ points); middle $\mathrm{AA}$ ( $7-5$ points); or lower $\mathrm{AA}$ ( $<4$ points), based on the tertile values of this score.

\subsubsection{Cardiorespiratory fitness}

Health-related components of physical fitness were evaluated using the Fitnessgram Test Battery, version 8.0. The Fitnessgram is included in the physical education curriculum, and the five tests recommended in the Portuguese National Program (curl-up, push-up, trunk lift, shuttle-run, and the modified back saver sit-and-reach) were used in this study. All tests were conducted according to the Fitnessgram measurement procedures (Welk \& Meredith, 2008).

For the purpose of the present analysis we only considered the 20-m shuttle-run test as a way to evaluate cardiorespiratory fitness. This test requires participants to run back and forth between two lines set $20 \mathrm{~m}$ apart. Running speed started at $8.5 \mathrm{~km} / \mathrm{h}$ and increased by $0.5 \mathrm{~km} / \mathrm{h}$ each minute, reaching $18.0 \mathrm{~km} / \mathrm{h}$ at minute 20. Each level was announced on the tape. The participants were told to keep up with the pacer until exhausted. The test was finished when the participant failed to reach the end lines concurrent with the audio signals on two consecutive occasions. Otherwise, the test ended when the subject stopped because of fatigue. Participants were encouraged to keep running as long as possible throughout the course of the test. The number of shuttles performed was recorded. Age- and sexadjusted $z$-scores were computed, because the age and sex-specific cut-off points of the Fitnessgram criteria are only developed for children aged 10 years old or older, and most participants in this study were nine years old.

\subsubsection{Motor coordination}

MC was evaluated with the body coordination test, Körperkoordination Test für Kinder (KTK), developed for German children (aged 5-15 years) (Kiphard \& Schiling, 1974). The KTK battery has four items:

Balance: the child walks backward on three balance beams each $3 \mathrm{~m}$ in length, $5 \mathrm{~cm}$ in height, but with decreasing widths of $6,4.5$ and $3 \mathrm{~cm}$. The child has three attempts at each beam; the number of successful steps is recorded; a maximum of 24 steps (eight per trial) were counted for each balance beam, which comprises a maximum of 72 steps.

Jumping laterally: the child makes consecutive jumps from side to side over a small beam $(60 \mathrm{~cm} \times 4 \mathrm{~cm} \times 2 \mathrm{~cm}$ ) as quickly as possible for $15 \mathrm{~s}$. The child is instructed to keep his/her feet together; the number of correct jumps in two trials was summed.

Hopping on one leg over an obstacle: the child was instructed to hop on one foot at a time over a stack of foam blocks after a short run-up. After a successful hop with each foot (the child clears the block without touching it and continues to hop on the same foot at least two times), the height was increased by adding a block $(50 \mathrm{~cm} \times 20 \mathrm{~cm} \times 5 \mathrm{~cm})$. The child had three attempts at each height and on each foot; three, two or one point(s) was/were awarded for a successful performance on the first, second or third trial, respectively; a maximum of 39 points (12 stacks blocks) could be scored for each leg (maximum score 78).

Shifting platforms: the child began by standing with both feet on one platform $(25 \mathrm{~cm} \times 25 \mathrm{~cm} \times 2 \mathrm{~cm}$ ) supported on four legs, $3.7 \mathrm{~cm}$ in height and holding a second identical platform in his/her hands; the child was then instructed to place the second platform alongside the first and to step onto it; the first box was then lifted and placed alongside the second and the child stepped onto it; this sequence continued for $20 \mathrm{~s}$. Each successful transfer from one platform to the next earned two points (one for shifting the platform, the other for transferring the body); the number of points in $20 \mathrm{~s}$ was recorded and summed for two trials. If the child fell off the platform in the process, he/she simply stepped back onto the platform and continued the test.

Although some of the items in the KTK appear to measure specific components of motor performance, e.g., dynamic balance, speed and agility, balance and power, the four tests were loaded in a single factor when analyzed with other items (Kiphard \& Schiling, 1974). Hence, the four items were utilized together as a global indicator of MC, the "motor quotient". Each performance item was scored relative to gender- and age-specific reference values for the population upon which the KTK was 
established. The sum of the standardized scores for the four items provided the motor quotient. Using the motor quotient children were then categorized as having: MC disorders ( $<70$ motor quotient); MC insufficiency $(71 \leqslant$ motor quotient $\leqslant 85)$; normal $M C \quad(86 \leqslant$ motor quotient $\leqslant 115)$; good MC $(115 \leqslant$ motor quotient $\leqslant 130)$; or very good MC $(131 \leqslant$ motor quotient $\leqslant 145)$.

The psychometric characteristics of the KTK have been documented in literature (Kiphard \& Schiling, 1974). The test-retest reliability coefficient for the raw score on the total test battery was .97 , while corresponding coefficients for individual tests ranged from .80 to .96 . Factor analysis of the four individual tests resulted in a single factor labeled gross MC. The percentage of total variance in MC explained by the four tests varied from $81 \%$ at 6 years to $98 \%$ at 9 years (Kiphard \& Schiling, 1974). Inter-correlations among the four tests varied from .60 to .81 for the reference sample of 1228 children. Both the factor analysis and inter-correlations thus indicated acceptable construct validity. Validity was further determined through differentiation of normal from disabled children. The KTK test differentiated $91 \%$ of children with brain damage from normal children. Participants were classified as having: MC disorders, MC insufficiency, normal MC, good MC or very good MC, according to the KTK reference values described above. Participants with good MC were recoded and combined with those with normal MC due to their small sample size (1.2\%).

\subsubsection{Sociodemographics}

Each child's date of birth, gender, and socio-economic status was extracted from the schools' administrative record systems. The socio-economic status records used by the Portuguese Ministry of Education are based on annual family income: children may be eligible for benefit A, eligible for benefit B, or not eligible. These categories were used as a proxy measurement of family socio-economic status (Education, 2009). According to the Portuguese Ministry of Education, those eligible for benefit A receive books, school supplies, and meals for free; those eligible for benefit $\mathrm{B}$ receive $50 \%$ of the books required and a $50 \%$ discount on meals.

\subsubsection{Anthropometrics}

Weight was measured to the nearest $0.1 \mathrm{~kg}$ using a regularly calibrated digital scale (Tanita TBF-300), while the child was wearing light clothing without shoes. Height was measured to the nearest millimeter with a field stadiometer (Seca 220). The body mass index $\left(\mathrm{kg} \mathrm{m}^{-2}\right)$ was calculated according to cut-off points defined by Cole, Bellizzi, Flegal, and Dietz (2000).

\subsection{Statistical analysis}

Two tailed $t$-test compared gender differences in continuous variables. Binary logistic regression was used to analyze the influence of MC on AA, adjusting for cardiorespiratory fitness, body mass index and socio-economic status. In this regression analysis children belonging to the lower and middle tertiles of AA were grouped into one category - models were constructed separately for girls and boys. In each model all variables were tested simultaneously.

Statistics was performed using Predictive Analytics Software (IBM - PASW Statistics 18 - Statistical Program for Windows), formerly known as SPSS (Statistical Package for the Social Sciences). A $p$-value of $<.05$ denoted statistical significance.

\section{Results}

Boys had, on average, significantly higher levels of gross MC and fitness compared with girls $(p<.001$ for both), Table 1 .

As shown in Table 2, 51.6\% of the entire sample exhibited MC disorders or MC insufficiency and none of the participants showed very good MC. In both, Portuguese Language and Mathematics exams, none of the participants scored $\mathrm{E}$, and more boys than girls scored $\mathrm{A}$ and $\mathrm{D}$.

Children with MC insufficiency or MC disorders exhibited a higher probability of having low AA, compared with those with normal coordination $(p<.05$ for trend in both genders; see Tables 3 and 4$)$. 
Table 1

Participants' characteristics.

\begin{tabular}{lcccc}
\hline & Whole sample $(n=596)$ & Girls $(n=281)$ & Boys $(n=315)$ & $p^{*}$ \\
\hline Age (years) & $9.7 \pm 0.6$ & $9.7 \pm 0.5$ & $9.7 \pm 0.6$ & .552 \\
Cardiorespiratory Fitness (number of laps) & $19.9 \pm 11.3$ & $16.6 \pm 8.0$ & $22.8 \pm 13.0$ & .000 \\
Motor Coordination (motor quotient) & $85.7 \pm 14.4$ & $81.7 \pm 14.5$ & $89.3 \pm 13.4$ & .000 \\
Body Mass Index $\left(\mathrm{kg} \mathrm{m}^{-2}\right)$ & $18.6 \pm 3.3$ & $18.6 \pm 3.3$ & $18.6 \pm 3.3$ & .934 \\
\hline
\end{tabular}

Portugal, academic year 2009/2010.

* $t$-Test compared gender differences.

\section{Discussion}

The results of this study indicated that children of both genders with low gross MC had a higher probability of having low AA, after adjusting for cardiorespiratory fitness, body mass index, and socio-economic status.

There are potential biological, psychological, and social mechanisms that may help explain this relationship. Coordinative exercise (exercises strengthening various coordination abilities) involve an activation of the cerebellum, which influences motor functions (Gao et al., 1996) as well as attention (Courchesne et al., 1994), working memory (Klingberg, Kawashima, \& Roland, 1996), and verbal learning and memory (Andreasen et al., 1995). Additionally, the frontal lobes play an important role in mediating both MC (Hernandez et al., 2002) and cognitive functions (Miller \& Cohen, 2001). An interventional study performed by Budde et al. (2008) aiming to investigate the effect of 10 min of physical exercise (coordination exercises vs. non-specific physical education lessons) on concentration and attention performance in a school setting revealed enhanced attention and concentration performance in both groups, with significantly higher enhancement in the group that performed coordination exercises. Furthermore, they suggest that coordination exercises lead to a facilitation of neuronal networks that results in a pre-activation of cortical activities that are responsible for cognitive functions such as attention (Budde et al., 2008).

Table 2

Prevalence of motor coordination and academic achievement.

\begin{tabular}{|c|c|c|c|c|c|c|}
\hline & \multicolumn{2}{|c|}{ Whole sample $(n=596)$} & \multicolumn{2}{|c|}{ Girls $(n=281)$} & \multicolumn{2}{|c|}{ Boys $(n=315)$} \\
\hline & $n$ & $\%$ & $n$ & $\%$ & $n$ & $\%$ \\
\hline \multicolumn{7}{|l|}{ Motor coordination } \\
\hline Motor coordination disorders & 86 & 14.4 & 63 & 22.4 & 23 & 7.3 \\
\hline Motor coordination insufficiency & 222 & 37.3 & 107 & 38.1 & 115 & 36.5 \\
\hline Normal motor coordination & 281 & 47.1 & 110 & 39.1 & 171 & 54.3 \\
\hline Good motor coordination & 7 & 1.2 & 1 & 0.4 & 6 & 1.9 \\
\hline Very good motor coordination & 0 & 0 & 0 & 0 & 0 & 0 \\
\hline \multicolumn{7}{|l|}{ Portuguese language exam } \\
\hline A & 64 & 10.7 & 27 & 9.6 & 37 & 11.8 \\
\hline $\mathrm{B}$ & 210 & 35.2 & 107 & 38.1 & 103 & 32.7 \\
\hline $\mathrm{C}$ & 255 & 42.8 & 121 & 43.1 & 134 & 42.5 \\
\hline $\mathrm{D}$ & 67 & 11.3 & 26 & 9.2 & 41 & 13.0 \\
\hline E & 0 & 0 & 0 & 0 & 0 & 0 \\
\hline \multicolumn{7}{|l|}{ Mathematic exam } \\
\hline A & 114 & 19.1 & 48 & 17.1 & 66 & 21.0 \\
\hline $\mathrm{B}$ & 201 & 33.7 & 100 & 35.6 & 101 & 32.0 \\
\hline $\mathrm{C}$ & 215 & 36.1 & 102 & 36.3 & 113 & 35.9 \\
\hline $\mathrm{D}$ & 66 & 11.1 & 31 & 11.0 & 35 & 11.1 \\
\hline $\mathrm{E}$ & 0 & 0 & 0 & 0 & 0 & 0 \\
\hline
\end{tabular}

Portugal, academic year 2009/2010. 
Table 3

Odds ratios and 95\% confidence Intervals from binary logistic regression model predicting low academic achievement, for girls.

\begin{tabular}{|c|c|c|c|c|c|c|c|c|}
\hline \multirow[t]{3}{*}{ Boys } & \multicolumn{8}{|c|}{ Low academic achievement } \\
\hline & \multicolumn{4}{|c|}{ Unadjusted model } & \multicolumn{4}{|c|}{ Adjusted model $^{\mathrm{a}}$} \\
\hline & OR & $95 \% \mathrm{CI}$ & $p$ & $p$ for trend & OR & $95 \% \mathrm{CI}$ & $p$ & $p$ for trend \\
\hline Normal/good motor coordination ${ }^{\mathrm{b}}$ & 1 & & & $<.001$ & 1 & & & $<.001$ \\
\hline Motor coordination insufficiency & 1.938 & $(0.778-4.828)$ & .155 & & 2.496 & $(0.941-6.623)$ & $<.066$ & \\
\hline Motor coordination disorders & 5.150 & $(2.087-12.711)$ & $<.001$ & & 7.861 & $(2.739-22.559)$ & $<.001$ & \\
\hline Body mass index & & & & & 0.916 & $(0.816-1.029)$ & .139 & \\
\hline Cardiorespiratory fitness & & & & & 1.223 & $(0.815-1.837)$ & .331 & \\
\hline Socioeconomic status ${ }^{\mathrm{b}}$ (not eligible) & & & & & 1 & & & .698 \\
\hline Socioeconomic status (benefit A) & & & & & 0.678 & $(0.246-1.865)$ & .451 & \\
\hline Socioeconomic status (benefit B) & & & & & 0.744 & $(0.330-1.681)$ & .477 & \\
\hline
\end{tabular}

Portugal, academic year 2009/2010.

OR - Odds Ratio.

$\mathrm{CI}$ - Confidence Intervals.

a Adjusted for socioeconomic status, body mass index and cardiorespiratory fitness.

b Reference category.

Table 4

Odds ratios and 95\% confidence Intervals from binary logistic regression model predicting low academic achievement, for boys.

\begin{tabular}{|c|c|c|c|c|c|c|c|c|}
\hline \multirow[t]{3}{*}{ Boys } & \multicolumn{8}{|c|}{ Low academic achievement } \\
\hline & \multicolumn{4}{|c|}{ Unadjusted model } & \multicolumn{4}{|c|}{ Adjusted model $^{\mathrm{a}}$} \\
\hline & OR & $95 \% \mathrm{CI}$ & $p$ & $p$ for trend & OR & $95 \% \mathrm{CI}$ & $p$ & $p$ for trend \\
\hline Normal/good motor coordination ${ }^{\mathrm{b}}$ & 1 & & & $<.026$ & 1 & & & .006 \\
\hline Motor coordination insufficiency & 1.483 & $(0.769-2.862)$ & $<.240$ & & 1.868 & $(0.902-3.865)$ & $<.092$ & \\
\hline Motor coordination disorders & 3.758 & $(1.428-9.886)$ & .007 & & 6.815 & $(2.075-22.379)$ & .002 & \\
\hline Body mass index & & & & & 0.841 & $(0.741-0.954)$ & .007 & \\
\hline Cardiorespiratory fitness & & & & & 1.021 & $(0.710-1.469)$ & .910 & \\
\hline Socioeconomic status ${ }^{\mathrm{b}}$ (not eligible) & & & & & 1 & & & .016 \\
\hline Socioeconomic status (benefit A) & & & & & 0.867 & $(0.360-2.090)$ & .750 & \\
\hline Socioeconomic status (benefit B) & & & & & 0.369 & $(0.175-0.778)$ & .009 & \\
\hline
\end{tabular}

Portugal, academic year 2009/2010.

OR - Odds Ratio.

$\mathrm{CI}$ - Confidence Intervals.

a Adjusted for socioeconomic status, body mass index and cardiorespiratory fitness.

b Reference category.

Better gross MC results may reflect better overall health, as has been suggested in the case of physical fitness (Chomitz et al., 2009) (i.e., better nutrition, more PA and healthier weight status), and good health may contribute positively to AA. As the literature points out, high levels of motor competence/ skill are positively associated with PA (Wrotniak, Epstein, Dorn, Jones, \& Kondilis, 2006). Cognitive facilitation by PA is presumably attributable to a direct improvement in cerebral circulation (of glucose, oxygen and energetic substances) and the alteration of neurotransmitter actions in the central nervous system (acetycholine, dopamine, norepinephrine, epinephrine, adrenocorticotropic hormone and vasopressin) (Kashihara, Maruyama, Murota, \& Nakahara, 2009). Taras (2005) indicates that PA increases blood flow to the brain and raises the levels of hormones (norepinephrine and endorphins) that reduce stress, improve mood, and induce a calming effect after exercise, possibly leading to an improvement in AA (Taras, 2005). It has also been suggested that increased PA may induce arousal and reduce boredom, leading to increased attention span and better concentration (Shephard, 1996). Additionally, PA may increase feelings of self-efficacy and self-esteem, which can improve class behavior as well as AA. Furthermore, it is assumed that children who participate in PA that promotes cooperation, sharing, and rule-following learn skills that transfer to classroom settings (Taras, 2005). 
It is of importance to note that children with poor MC report systematically less participation in organized and free-play activities than their typically developing peers (activity deficit) (Bouffard, Watkinson, Thompson, Causgrove Dunn, \& Romanow, 1996; Cairney, Hay, Faught, Mandigo, \& Flouris, 2005), and these differences tend to persisted over time (Cairney, Hay, Veldhuizen, Missiuna, \& Faught, 2010); therefore, it is possible that these children are not provided with the same opportunity to enhance AA given the benefits of PA on AA.

Our results also showed that boys had higher levels of gross MC and better performance on cardiorespiratory fitness tests than girls. This finding is supported by previous longitudinal research that found that boys had consistently higher results in both MC and physical fitness than girls at each observation (Lopes, Rodrigues, Maia, \& Malina, 2009; Pereira et al., 2010). Perhaps the types of sports and PA in which boys are more often involved, i.e., those that require eye-hand (or foot) coordination (evident in a variety of ball games), give them more opportunities to improve their cardiorespiratory fitness and refine their MC.

Only $48.8 \%$ of our study participants were classified as having at least normal MC and none showed very good MC. These results are in line with those reported in a study with Portuguese children aged 6-10 years old (Maia \& Lopes, 2002). However, our gross MC numbers are considerably lower than those observed by others (Graf et al., 2004; Vandorpe et al., 2011). In a study with German children aged 6-9 years old, Graf et al. (2004) found that only $31.3 \%$ of participants showed lower than normal MC. Vandorpe et al. (2011), in a study of Belgian children aged 6-11 years, found that only $21.1 \%$ demonstrated lower than normal MC. In the original German (1974) standardization sample with children aged 6-11, only 16\% demonstrated lower than normal MC (Kiphard \& Schiling, 1974). The low gross MC levels in Portuguese children may possibly be explained partially by the fact that Portuguese children have one of the highest rates of obesity in Europe (Sardinha et al., 2011). Indeed, several studies have described that overweight children have poor results on motor skill tests when compared with their normal-weight counterparts (Graf et al., 2004; Okely, Booth, \& Chey, 2004). Additionally, Portuguese children and adolescents have lower levels of PA (Baptista et al., 2012) compared to their European counterparts, a characteristic that correlates with low MC (Okely, Booth, \& Patterson, 2001). Furthermore, KTK norms and cut-off values are based on German children tested 36 years ago, while the literature has shown that children's physical fitness (Tomkinson, Leger, Olds, \& Cazorla, 2003) and PA (Knuth \& Hallal, 2009) are declining; as motor skills are positively associated with both physical fitness (Hands, Larkin, Parker, Straker, \& Perry, 2009) and PA (Williams et al., 2008; Wrotniak et al., 2006), perhaps MC levels are decreasing as well. Indeed, Prätorius and Milani (2004) have shown that over the last 30 years, the percentage of German children with low MC has increased substantially, from $16 \%$ in the KTK test's original validation to a level of $38 \%$ in contemporary children.

Schools are excellent settings in which to provide students with the opportunity for daily PA, to teach the importance of regular PA for health, and to build skills that support active lifestyles. Promoting active lifestyles from a young age is widely recognized as beneficial, and the health benefits of regular PA are extensively acknowledged (Andersen et al., 2006; Strong et al., 2005). The incorporation of PA into daily life and the achievement of recommended PA levels for the maintenance of good health are major public health challenges. Physical education lessons and school recesses are ideal settings in which to develop children's fundamental movement skills and increase PA and fitness (van Beurden et al., 2003), while also contributing to one of the primary missions of schools, i.e., the promotion of academic performance (Dwyer, Sallis, Blizzard, Lazarus, \& Dean, 2001).

Given the importance of assessment and evaluation in the education and health fields and the pressures that educational agents are under to achieve academic success for all students, indicators of educational achievement, health, and functional status may allow educators and policy makers to make better informed decisions (Lloyd, Colley, \& Tremblay, 2010). Therefore, understanding the relationship between MC and AA is important for ensuring the appropriate assignment of resources as well as the implementation of programs to develop children's health-related behaviors. This study highlights the necessity of providing opportunities for children to engage in PA structured and unstructured that promote a diversity of motor skills, since gross MC seems to play such an important role in AA. 


\section{Strengths and limitations}

This study has some limitations that need to be recognized. The data has been derived from a cross-sectional study so the results do not indicate causality. Our sample is not representative of the Portuguese population and therefore our findings are not generalizable. The use of shuttle-run tests to assess aerobic fitness in children with motor problems is controversial, and has been criticized by Armstrong and Welsman (1997) and Hands and Larkin (2006) for being overly vulnerable to both motivational and environmental effects. Indeed, field-based measures of aerobic capacity rely on the internal motivation of the participants to perform to exhaustion (Rivilis et al., 2011), a circumstance that could be particularly challenging for children with developmental coordination disorders because they generally report less confidence in their physical abilities and may be unlikely to persist in their tasks (Cairney, Hay, Wade, Faught, \& Flouris, 2006). Nevertheless, a recent study has shown that the shuttle-run test is moderately to fairly well correlated with lab based cycle ergometer tests for assessing cardiorespiratory fitness in children with and without developmental coordination disorders (Cairney, Hay, Veldhuizen, \& Faught, 2010).

Overall, the strengths of our study include the use of direct indicators of AA, namely, scores on standardized national exams; the inclusion of potential confounding factors such as socio-economic status, which is recognized as a major factor in academic performance (Coe et al., 2006); the use of cardiorespiratory fitness, because it was suggested that this could mediate the relationship between PA and AA (Kwak et al., 2009), and the use of body mass index, which has been documented as inversely related with MC (Graf et al., 2004; Okely et al., 2004).

More research is needed to further study the relationship between MC and AA. Longitudinal and interventional studies would provide information on the direction of this association.

\section{Conclusions}

In this cross-sectional study, children of both genders with lower MC had higher odds of having low AA, after adjusting for potential confounding factors. The early identification of children with poor MC is crucial to implementing activities that develop health-related behaviors.

\section{Conflict of interest statement}

The authors declare that there are no conflicts of interest.

\section{Acknowledgment}

The first author was supported by the Portuguese FCT-MEC Grant [BD/43808/2008].

\section{References}

Ahamed, Y., Macdonald, H., Reed, K., Naylor, P. J., Liu-Ambrose, T., \& McKay, H. (2007). School-based physical activity does not compromise children's academic performance. Medicine and Science in Sports and Exercise, 39, 371-376.

Alloway, T. P. (2007). Working memory, reading, and mathematical skills in children with developmental coordination disorder. Journal of Experimental Child Psychology, 96, 20-36.

Alloway, T. P., \& Alloway, R. G. (2010). Investigating the predictive roles of working memory and IQ in academic attainment. Journal of Experimental Child Psychology, 106, 20-29.

Andersen, L. B., Harro, M., Sardinha, L. B., Froberg, K., Ekelund, U., Brage, S., et al (2006). Physical activity and clustered cardiovascular risk in children: A cross-sectional study (The European Youth Heart Study). Lancet, 368(9532), 299-304.

Andreasen, N. C., O'Leary, D. S., Arndt, S., Cizadlo, T., Hurtig, R., Rezai, K., et al (1995). Short-term and long-term verbal memory: A positron emission tomography study. Proceedings of the National Academy of Sciences USA, 92, 5111-5115.

Armstrong, N., \& Welsman, J. (1997). Young people and physical activity. Oxford, UK: Oxford University Press.

Baptista, F., Santos, D. A., Silva, A. M., Mota, J., Santos, R., Vale, S., et al (2012). Prevalence of the Portuguese population attaining sufficient physical activity. Medicine and Science in Sports and Exercise, 44, 466-473.

Bouffard, M., Watkinson, E., Thompson, L., Causgrove Dunn, J., \& Romanow, S. (1996). A test of the activity deficit hypothesis with children with movement difficulties. Adapted Physical Activity Quartely, 13, 61-73.

Budde, H., Voelcker-Rehage, C., Pietrabyk-Kendziorra, S., Ribeiro, P., \& Tidow, G. (2008). Acute coordinative exercise improves attentional performance in adolescents. Neuroscience Letters, 441, 219-223. 
Cairney, J., Hay, J., Faught, B., Mandigo, J., \& Flouris, A. (2005). Developmental coordination disorder, self-efficacy toward physical activity and play: Does gender matter? Adapted Physical Activity Quarterly, 22, 67-82.

Cairney, J., Hay, J., Veldhuizen, S., \& Faught, B. (2010a). Comparison of VO2 maximum obtained from $20 \mathrm{~m}$ shuttle run and cycle ergometer in children with and without developmental coordination disorder. Research in Developmental Disabilities, 31 , 1332-1339.

Cairney, J., Hay, J. A., Veldhuizen, S., Missiuna, C., \& Faught, B. E. (2010b). Developmental coordination disorder, sex, and activity deficit over time: A longitudinal analysis of participation trajectories in children with and without coordination difficulties. Developmental Medicine and Child Neurology, 52, e67-e72.

Cairney, J., Hay, J. A., Wade, T. J., Faught, B. E., \& Flouris, A. (2006). Developmental coordination disorder and aerobic fitness: Is it all in their heads or is measurement still the problem? American Journal of Human Biology, 18, 66-70.

Carlson, S. A., Fulton, J. E., Lee, S. M., Maynard, L. M., Brown, D. R., Kohl, H. W. III, et al (2008). Physical education and academic achievement in elementary school: Data from the early childhood longitudinal study. American Journal of Public Health, 98, 721-727.

Castelli, D. M., Hillman, C. H., Buck, S. M., \& Erwin, H. E. (2007). Physical fitness and academic achievement in third- and fifthgrade students. Journal of Sports and Exercise Psychology, 29, 239-252.

Chomitz, V. R., Slining, M. M., McGowan, R. J., Mitchell, S. E., Dawson, G. F., \& Hacker, K. A. (2009). Is there a relationship between physical fitness and academic achievement? Positive results from public school children in the northeastern United States. Journal of School Health, 79, 30-37.

Clark, J. E. (2005). From the beginning: A developmental perspective on movement and mobility. Quest, 57, 3-45.

Clark, J. E., \& Metcalfe, J. M. (2002). The mountain of motor development: A metaphor. In J. E. C. J. H. Humphrey (Ed.), Motor development: Research and reviews (pp. 163-190). Reston, VA: NASPE Publications.

Coe, D. P., Pivarnik, J. M., Womack, C. J., Reeves, M. J., \& Malina, R. M. (2006). Effect of physical education and activity levels on academic achievement in children. Medicine and Science in Sports and Exercise, 38, 1515-1519.

Cole, T. J., Bellizzi, M. C., Flegal, K. M., \& Dietz, W. H. (2000). Establishing a standard definition for child overweight and obesity worldwide: International survey. BMJ, 320, 1240-1243.

Courchesne, E., Townsend, J., Akshoomoff, N. A., Saitoh, O., Yeung-Courchesne, R., Lincoln, A. J., et al (1994). Impairment in shifting attention in autistic and cerebellar patients. Behavioral Neuroscience, 108, 848-865.

Dwyer, G. M., Baur, L. A., \& Hardy, L. L. (2009). The challenge of understanding and assessing physical activity in preschool-age children: Thinking beyond the framework of intensity, duration and frequency of activity. Journal of Science and Medicine in Sport, 12, 534-536.

Dwyer, T., Sallis, J. F., Blizzard, L., Lazarus, R., \& Dean, K. (2001). Relation of academic performance to physical activity and fitness in children. Pediatric Exercise Science, 13, 225-237.

Education, P. M. O. Family socio-economic status. (2009). <http://www.min-edu.pt/np3/4127.html> Retrieved 10.10.2010.

Erickson, I. (2008). Motor skills, attention and academic achievements. An intervention study in school years 1-3. British Educational Research Journal, 34, 301-313.

Ertl, H. (2006). Educational standards and changing in discourse on education: The reception and consequences of the PISA study in Germany. Oxford Review of Education, 32, 619-634.

Etnier, J. L., Nowell, P. M., Landers, D. M., \& Sibley, B. A. (2006). A meta-regression to examine the relationship between aerobic fitness and cognitive performance. Brain Research Reviews, 52, 119-130.

Eveland-Sayers, B. M., Farley, R. S., Fuller, D. K., Morgan, D. W., \& Caputo, J. L. (2009). Physical fitness and academic achievement in elementary school children. Journal of Physical Activity and Health, 6, 99-104.

Fox, C. K., Barr-Anderson, D., Neumark-Sztainer, D., \& Wall, M. (2010). Physical activity and sports team participation: Associations with academic outcomes in middle school and high school students. Journal of School Health, 80, 31-37.

Gao, J. H., Parsons, L. M., Bower, J. M., Xiong, J., Li, J., \& Fox, P. T. (1996). Cerebellum implicated in sensory acquisition and discrimination rather than motor control. Science, 272(5261), 545-547.

Graf, C., Koch, B., Kretschmann-Kandel, E., Falkowski, G., Christ, H., Coburger, S., et al (2004). Correlation between BMI, leisure habits and motor abilities in childhood (CHILT-project). International Journal of Obesity Related Metabolic Disorders, 28, 22-26.

Grissom, J. B. (2005). Physical fitness and academic achievement. Pediatric Exercise Physiology, 8, 11-25.

Haga, M. (2008). The relationship between physical fitness and motor competence in children. Child: Care Health and Development, 34, 329-334.

Hands, B., \& Larkin, D. (2006). Physical fitness differences in children with and without motor learning difficulties. European Journal of Special Needs Education, 21, 447-456.

Hands, B., Larkin, D., Parker, H., Straker, L., \& Perry, M. (2009). The relationship among physical activity, motor competence and health-related fitness in 14-year-old adolescents. Scandinavian Journal of Medicine and Science in Sports, 19, 655-663.

Hernandez, M. T., Sauerwein, H. C., Jambaqué, I., De Guise, E., Lussier, F., Lortie, A., et al (2002). Deficits in executive functions and motor coordination in children with frontal lobe epilepsy. Neuropsychologia, 40, 384-400.

Hillman, C. H., Erickson, K. I., \& Kramer, A. F. (2008). Be smart, exercise your heart: Exercise effects on brain and cognition. Nature Reviews Neuroscience, 9, 58-65.

Kashihara, K., Maruyama, T., Murota, M., \& Nakahara, Y. (2009). Positive effects of acute and moderate physical exercise on cognitive function. Journal of Physiological Anthropology, 28, 155-164.

Kiphard, E. J., \& Schiling, F. (1974). Körperkoordination Test für Kinder, KTK. Weinheim: Beltz Test Gmbh.

Klingberg, T., Kawashima, R., \& Roland, P. E. (1996). Activation of multi-modal cortical areas underlies short-term memory. European Journal of Neuroscience, 8, 1965-1971.

Knight, D., \& Rizzuto, T. (1993). Relations for children in grades 2, 3, and 4 between balance skills and academic achievement. Perceptual and Motor Skills, 76, 1296-1298.

Knuth, A. G., \& Hallal, P. C. (2009). Temporal trends in physical activity: A systematic review. Journal of Physical Activity and Health, 6, 548-559.

Kwak, L., Kremers, S. P., Bergman, P., Ruiz, J. R., Rizzo, N. S., \& Sjostrom, M. (2009). Associations between physical activity, fitness, and academic achievement. Journal of Pediatrics, 155, 914-918. 
Lloyd, M., Colley, R. C., \& Tremblay, M. S. (2010). Advancing the debate on 'fitness testing' for children: Perhaps we're riding the wrong animal. Pediatric Exercise Science, 22, 176-182.

Lopes, V., Rodrigues, L., Maia, J. A. R., \& Malina, R. M. (2009). Motor coordination as predictor of physical activity in childhood. Scandinavian Journal of Medicine and Science in Sports, 21, 663-669.

Lubans, D. R., Morgan, P. J., Cliff, D. P., Barnett, L. M., \& Okely, A. D. (2010). Fundamental movement skills in children and adolescents: Review of associated health benefits. Sports Medicine, 40, 1019-1035.

Maia, J. A. R., \& Lopes, V. (2002). Estudo do crescimento somático, aptidão física e capacidade de coordenação corporal de crianças do 1 ciclo do ensino básico da região autónoma dos açores. Porto: Faculdade de Ciências do Desporto e de Educação Física da Universidade do Porto. Direcção Regional de Educação Física e Desporto da Região Autónoma dos Açores e Direcção Regional da Ciência e Tecnologia.

Malina, R. M. (1996). Tracking of physical activity and physical fitness across the lifespan. Research Quarterly Exercise and Sport, 67, S48-S57.

Miller, E. K., \& Cohen, J. D. (2001). An integrative theory of prefrontal cortex function. Annual Reviews of Neuroscience, 24, 167-202.

Niederer, I., Kriemler, S., Gut, J., Hartmann, T., Schindler, C., Barral, J., et al (2011). Relationship of aerobic fitness and motor skills with memory and attention in preschoolers (Ballabeina): A cross-sectional and longitudinal study. BMC Pediatrics, 11, 34.

Nourbakhsh, P. (2006). Perceptual-motor abilities and their relationships with academic performance of fifth grade pupils in comparison with Oseretsky scale. Kinesiology, 38, 40-48.

Okely, A. D., Booth, M. L., \& Chey, T. (2004). Relationships between body composition and fundamental movement skills among children and adolescents. Research Quarterly for Exercise and Sport, 75, 238-247.

Okely, A. D., Booth, M. L., \& Patterson, J. W. (2001). Relationship of physical activity to fundamental movement skills among adolescents. Medicine and Science in Sports and Exercise, 33, 1899-1904.

Payne, G., \& Isaacs, L. (1998). Human motor development: A lifespan approach. California: Mayfield Publishing Company.

Pereira, S. A., Seabra, A. T., Silva, R. G., Zhu, W., Beunen, G. P., \& Maia, J. A. (2010). Correlates of health-related physical fitness levels of Portuguese children. International Journal of Pediatric Obesity, 6, 53-59.

Piek, J. P., Baynam, G. B., \& Barrett, N. C. (2006). The relationship between fine and gross motor ability, self-perceptions and selfworth in children and adolescents. Human Movement Science, 25, 65-75.

Piek, J. P., Dawson, L., Smith, L. M., \& Gasson, N. (2008). The role of early fine and gross motor development on later motor and cognitive ability. Human Movement Science, 27, 668-681.

Planinsec, J. (2002). Relations between the motor and cognitive dimensions of preschool girls and boys. Perceptual and Motor Skills, 94, 415-423.

Prätorius, B., \& Milani, T. L. (2004). Motorische Leistungsfähigkeit bei Kindern: Koordinations- und Gleichgewichtsfähigkeit: Untersuchung des Leistungsgefälles zwischen Kindern mit verschiedenen Sozialisationsbedingungen. Deutsche Zeitschtift für Sportmedizin, 55, 172-176.

Rasberry, C. N., Lee, S. M., Robin, L., Laris, B. A., Russell, L. A., Coyle, K. K., et al (2011). The association between school-based physical activity, including physical education, and academic performance. A systematic review of the literature. Preventive Medicine, 52, S10-S20.

Riethmuller, A. M., Jones, R., \& Okely, A. D. (2009). Efficacy of interventions to improve motor development in young children: A systematic review. Pediatrics, 124, e782-e792.

Rivilis, I., Hay, J., Cairney, J., Klentrou, P., Liu, J., \& Faught, B. E. (2011). Physical activity and fitness in children with developmental coordination disorder: A systematic review. Research in Developmental Disabilities, 32, 894-910.

Ruiz, J. R., Ortega, F. B., Castillo, R., Martin-Matillas, M., Kwak, L., Vicente-Rodriguez, G., et al (2010). Physical activity, fitness, weight status, and cognitive performance in adolescents. Journal of Pediatrics, 157, 917-922.

Sardinha, L. B., Santos, R., Vale, S., Silva, A. M., Ferreira, J. P., Raimundo, A. M., et al (2011). Prevalence of overweight and obesity among Portuguese youth: A study in a representative sample of 10 to 18 -year-old children and adolescents. International Journal of Pediatric Obesity, 6, e124-e128.

Serrien, D. J., Ivry, R. B., \& Swinnen, S. P. (2006). Dynamics of hemispheric specialization and integration in the context of motor control. Nature Reviews Neuroscience, 7, 160-166.

Shephard, R. J. (1996). Habitual physical activity and academic performance. Nutrition Reviews, 54, S32-S36.

Sigfusdottir, I. D., Kristjansson, A. L., \& Allegrante, J. P. (2007). Health behaviour and academic achievement in Icelandic school children. Health Education Research, 22, 70-80.

Son, S. H., \& Meisels, S. J. (2006). The relationship of young children's motor skills to later reading and math achievement. Merrill-Palmer Quarterly, 52, 755-778.

Sortor, J. M., \& Kulp, M. T. (2003). Are the results of the Beery-Buktenica developmental test of visual-motor integration and its subtests related to achievement test scores? Optometry and Vision Science, 80, 758-763.

Stodden, D. F., Goodway, J. D., Langendorfer, S. J., Robertson, M. A., Rudisill, M. E., Garcia, C., et al (2008). A developmental perspective on the role of motor skill competence in physical activity: An emergent relationship. Quest, 60, 290-306.

Strong, W. B., Malina, R. M., Blimkie, C. J., Daniels, S. R., Dishman, R. K., Gutin, B., et al (2005). Evidence based physical activity for school-age youth. Journal of Pediatrics, 146, 732-737.

Taras, H. (2005). Physical activity and student performance at school. Journal of School Health, 75, 214-218.

Tomkinson, G. R., Leger, L. A., Olds, T. S., \& Cazorla, G. (2003). Secular trends in the performance of children and adolescents (1980-2000): An analysis of 55 studies of the $20 \mathrm{~m}$ shuttle run test in 11 countries. Sports Medicine, 33, 285-300.

Tomkinson, G. R., \& Olds, T. S. (2007). Secular changes in pediatric aerobic fitness test performance. The global picture. Medicine and Sport Science, 50, 46-66.

Trudeau, F., \& Shephard, R. J. (2008). Physical education, school physical activity, school sports and academic performance. The International Journal of Behavioral Nutrition and Physical Activity, 5, 10.

Uhrich, T. A., \& Swalm, R. L. (2007). A pilot study of a possible effect from a motor task on reading performance. Perceptual and Motor Skills, 104, 1035-1041. 
van Beurden, E., Barnett, L. M., Zask, A., Dietrich, U. C., Brooks, L. O., \& Beard, J. (2003). Can we skill and activate children through primary school physical education lessons? "Move it Groove it". A collaborative health promotion intervention. Preventive Medicine, 36, 493-501.

Vandorpe, B., Vandendriessche, J., Lefevre, J., Pion, J., Vaeyens, R., Matthys, S., et al (2011). The KorperkoordinationsTest für Kinder: Reference values and suitability for 6-12-year-old children in Flanders. Scandinavian Journal of Medicine and Science in Sports, 21, 378-388.

Welk, G. J., \& Meredith, M. D. (Eds.). (2008). Fitnessgram/activitygram reference guide (3rd ed. Dallas, TX: The Cooper Institute.

Westendorp, M., Hartman, E., Houwen, S., Smith, J., \& Visscher, C. (2011). The relationship between gross motor skills and academic achievement in children with learning disabilities. Research in Developmental Disabilities, 32, 2773-2779.

Williams, H. G., Pfeiffer, K. A., O'Neill, J. R., Dowda, M., Mclver, K. L., Brown, W. H., et al (2008). Motor skill performance and physical activity in preschool children. Obesity, 16, 1421-1426.

Wrotniak, B. H., Epstein, L. H., Dorn, J. M., Jones, K. E., \& Kondilis, V. A. (2006). The relationship between motor proficiency and physical activity in children. Pediatrics, 118, e1758-1765. 